\title{
Curcumin induces apoptotic cell death in human pancreatic cancer cells via the miR-340/XIAP signaling pathway
}

\author{
DEYING YANG ${ }^{1}$, YUTAO LI $^{1}$ and DEQIN ZHAO ${ }^{2}$ \\ ${ }^{1}$ Department of Gastrointestinal Surgery, Linyi People's Hospital; ${ }^{2}$ Department of Neurosurgery, \\ Linyi Chinese Medicine Hospital, Linyi, Shandong 276000, P.R. China
}

Received September 18, 2015; Accepted March 3, 2017

DOI: $10.3892 / \mathrm{ol} .2017 .6321$

\begin{abstract}
The natural compound curcumin has previously been reported to inhibit pancreatic cancer cell growth. However, the underlying molecular mechanisms underlying this effect remain unclear. Results from the present study demonstrate that the miR-340/X-linked inhibitor of apoptosis (XIAP) signaling pathway mediates curcumin-induced pancreatic cancer cell apoptosis. miR-340 was identified to be significantly upregulated following curcumin treatment. In addition, treatment with curcumin or miR-340 induced pancreatic cancer cell apoptosis, whereas silencing endogenous miR-340 significantly inhibited the proapoptotic effect of curcumin. A luciferase reporter assay and western blot analysis identified that the oncogene XIAP is a direct target of miR-340. Furthermore, curcumin treatment significantly reduced XIAP expression, an effect that was rescued by treatment with anti-miR-340. The results of the present study suggest that the miR-340/XIAP signaling pathway is a downstream target of curcumin that mediates its proapoptotic effects on pancreatic cancer cells. This may provide the basis for novel treatment strategies for patients with pancreatic cancer.
\end{abstract}

\section{Introduction}

Pancreatic cancer an aggressive malignancy that is one of the leading causes of cancer-associated mortality worldwide (1). Due to the lack of effective treatment for pancreatic adenocarcinoma, the prognosis of this cancer type is very poor $(1,2)$. At present, the molecular mechanisms underlying pancreatic cancer remain unclear. Understanding how cancer-associated signaling molecules cooperate to regulate the pathogenesis of pancreatic cancer may aid in the development of novel treatments.

Correspondence to: Dr Deqin Zhao, Department of Neurosurgery, Linyi Chinese Medicine Hospital, 211 Jiefang Road, Linyi, Shandong 276000, P.R. China

E-mail: zhaodeqin2015@163.com

Key words: pancreatic cancer, microRNA-340, X-linked inhibitor of apoptosis, apoptosis
Curcumin is the primary active ingredient of the traditional Chinese medicinal plant Curcuma longa. Curcumin has been demonstrated to exert pleotropic beneficial functions, including antioxidative and anticancer effects (3-5). In addition, several previous studies have demonstrated that curcumin promotes apoptosis and inhibits the proliferation of pancreatic cancer cells (6-8). Previous studies have suggested that curcumin sensitizes drug-resistant cancer cells to chemotherapy, which indicates that curcumin may be effective in treating drug-resistant pancreatic cancer (9-11). Several intracellular targets of curcumin have been identified $(12,13)$; however, the molecular mechanism by which curcumin inhibits tumor growth remains unclear.

MicroRNAs (miRNAs/miRs) are a class of small non-coding RNAs that regulate gene expression and result in altered phenotypic changes in cancer cells. miRNAs have emerged as promising drug targets, and miRNA-based therapies have been proposed in various cancer models $(14,15)$. Several miRNAs have been revealed to serve key roles in the development and progression of pancreatic cancer (16-18). In addition, previous studies have demonstrated that miRNA signatures change following chemotherapy (19,20). Curcumin, a natural compound that exhibits low toxicity and yields strong antitumor effects, has been reported to significantly alter the miRNA expression profile in pancreatic cancers $(21,22)$. This indicates that miRNAs may mediate the antitumor effects of curcumin.

In the present study, miR-340, a tumor-suppressive miRNA (23), was investigated as a potential miRNA associated with the antitumor effects of curcumin on pancreatic cancer cells. This investigation revealed that miR-340 expression was markedly induced by curcumin treatment. In addition, an antiapoptotic protein named X-linked inhibitor of apoptosis (XIAP) was functionally targeted by miR-340, which likely confers the proapoptotic effect of curcumin. Therefore, the present study demonstrates that the miR-340/XIAP signaling pathway is essential for curcumin-induced pancreatic cancer cell apoptosis and may provide clinical insights for treating pancreatic cancer using curcumin.

\section{Materials and methods}

Cell culture, drug treatment and transfection. The pancreatic adenocarcinoma cell line PANC-1 and human embryonic 
kidney HEK293 cell line were purchased from the American Type Culture Collection (Manassas, VA, USA). Cells were cultured in Dulbecco's modified Eagle's medium (HyClone; GE Healthcare Life Sciences, Logan, UT, USA) supplemented with $10 \%$ fetal bovine serum (HyClone; GE Healthcare Life Sciences) in an incubator with $5 \% \mathrm{CO}_{2}$ at $37^{\circ} \mathrm{C}$. Negative controls for miR-340 and miR-340 inhibitor (NC; scrambled miRNA, supplied in each miRNA set), miR-340 (catalog no. miR10004692-1-5) or an miR-340 inhibitor (catalog no. miR20004692-1-5; Guangzhou RiboBio, Co., Ltd., Guangzhou, China) were transfected into cells using Lipofectamine ${ }^{\circledR}$ 2000 (Invitrogen; Thermo Fisher Scientific, Inc., Waltham, MA, USA) at a final concentration of $100 \mathrm{nM}$ according to the manufacturer's protocol. To avoid bacterial contamination, $100 \mathrm{U} / \mathrm{ml}$ penicillin and $100 \mu \mathrm{g} / \mathrm{ml}$ streptomycin were added to the culture media following transfection. Curcumin was purchased from Sigma-Aldrich (Merck KGaA, Darmstadt, Germany) and applied to cells at $2.5,5,10$ or $20 \mu \mathrm{M}$ for $72 \mathrm{~h}$. Cells were subjected to curcumin treatment $48 \mathrm{~h}$ following transfection.

Cell viability assay. Cell viability was measured using an MTT assay. PANC-1 cells were seeded into a 96-well plate at a concentration of $2.5 \times 10^{4} \mathrm{cells} / \mathrm{ml} /$ well. Following cell attachment for $24 \mathrm{~h}$, cells were treated with $2.5,5,10$ or $20 \mu \mathrm{mol} / \mathrm{l}$ curcumin for $72 \mathrm{~h}$, followed by incubation with $20 \mu \mathrm{l}$ MTT $(5 \mathrm{mg} / \mathrm{ml})$ for $4 \mathrm{~h}$. Dimethyl sulfoxide $(200 \mu \mathrm{l})$ was then added to each well to visualize the living cells. The raw data were obtained by measuring the absorbance value of the wells at $490 \mathrm{~nm}$ with a spectrophotometer.

Reverse transcription-quantitative polymerase chain reaction $(R T-q P C R)$. Following curcumin treatment, the cells were homogenized with TRIzol reagent (Invitrogen; Thermo Fisher Scientific, Inc.). A total of $0.2 \mathrm{ml}$ chloroform was then used to separate the upper phase that contained total RNA. The RNA samples were precipitated using isopropyl alcohol and washed with $70 \%$ ethanol. All the RNA samples were resolved in nuclease free water (Promega Corporation, Madison, WI, USA). To quantify the level of miR-340, the RNA samples were reverse-transcribed using a stem-loop primer set for miR-340 (catalog no. miRQ0004692-1-1 Guangzhou RiboBio, Co., Ltd.). The internal control gene used was U6 (provided in the miR-340 set, catalog no. miRQ0004692-1-1). Each qPCR volume was $25 \mu \mathrm{l}$ in total and the components were as follows: $12.5 \mu 12 \mathrm{X}$ SYBR Green mastermix (Promega Corporation, Madison, WI, USA), $7.5 \mu \mathrm{l}$ nuclease-free water and $5 \mu \mathrm{l} \mathrm{cDNA}$ template. The thermocycling conditions for qPCR were as follows: $94^{\circ} \mathrm{C}$ for $30 \mathrm{sec}, 58^{\circ} \mathrm{C}$ for $20 \mathrm{sec}$ and $72^{\circ} \mathrm{C}$ for $20 \mathrm{sec}$, for a total of 40 cycles. The fold change in miR-340 was calculated using the $2^{-\Delta \Delta C q}$ method (24).

Western blot analysis. Curcumin-treated cells were lysed using SDS lysis buffer supplemented with a protease inhibitor cocktail (Roche Diagnostics GmbH, Mannheim, Germany) and untreated cells were used as the control. The lysates were centrifuged at $12,000 \mathrm{xg}$ for $15 \mathrm{~min}$ at $4^{\circ} \mathrm{C}$. The supernatants were collected and mixed with SDS-PAGE buffer prior to protein denaturation at $100^{\circ} \mathrm{C}$ for 5 min prior to electrophoresis. The proteins (30 $\mu \mathrm{g} / \mathrm{lane})$ were separated via SDS-PAGE
(12\% gel) and then transferred onto polyvinylidene difluoride membranes. Proteins of interest were probed with their respective primary antibodies overnight at $4^{\circ} \mathrm{C}$. Rabbit polyclonal antibodies for cleaved caspase-3 (dilution, 1:1,000; catalog no. 9661), poly(ADP-ribose) polymerase (PARP) (dilution, 1:500; catalog no. 9542) and XIAP (dilution, 1:1,000; catalog no. 2042) were obtained from Cell Signaling Technology, Inc. (Danvers, MA, USA), and a mouse monoclonal antibody for $\beta$-actin (dilution, 1:2,000; catalog no. A5441) was purchased from Sigma-Aldrich (Merck KGaA). Horseradish peroxidase-conjugated goat anti-rabbit (dilution, 1:5,000; catalog no. sc-2004) and goat anti-mouse (dilution, 1:5,000; catalog no. sc-2005) secondary antibodies (Santa Cruz Biotechnology, Inc., Dallas, TX, USA) were subsequently incubated at room temperature for $1 \mathrm{~h}$ and used according to the host species of the primary antibodies. Protein bands were detected using the BeyoECL Plus P0018 kit (Beyotime Institute of Biotechnology, Haimen, China), and band intensities were determined using ImageJ software (version 2.1.4.7; National Institutes of Health, Bethesda, MD, USA).

Luciferase activity assay. To construct the luciferase reporter, a $600 \mathrm{bp}$ fragment of the XIAP 3'-untranslated region (UTR) that was extracted from the PANC1 cell line was amplified by PCR. Human cDNA, extracted from the PANC1 cell line, was used as a template and Pfu DNA polymerase (Promega Corporation) was used. The primers were as follows: Forward primer, 5'-TTCCTCAGCATA ACAGAGTT-3'; reverse primer, 5'-CAGGCTGGCATCATATACT-3'. Subsequently, this was subcloned into the pmirGLO plasmid. The plasmid containing the XIAP $3^{\prime}$-UTR and a pRL-TK plasmid, in addition to miR-340, anti-miR-340 or the NC was transfected into HEK293 cells $\left(2.5 \times 10^{4}\right.$ cells $\left./ \mathrm{ml}\right)$ that were seeded 1 day before transfection. Luciferase activity was tested $48 \mathrm{~h}$ after transfection. Cells were lysed, using lysis buffer (Dual Luciferase kit; Promega Corporation), and $20 \mu \mathrm{l}$ supernatant was used for each reaction. A total of $75 \mu 1$ firefly luciferase substrate was added to each mixture, mixed for $10 \mathrm{sec}$ and the luciferase activity was determined. Subsequently, $75 \mu 1$ Renilla luciferase substrate was added to each well and the activity was determined. Relative activity was determined as the ratio of firefly luciferase to Renilla luciferase using a GloMax ${ }^{\circledR}$-Multi Detection System (Promega Corporation) according to the manufacturer's protocol. Experiments were performed in triplicate. All the reagents use in the luciferase activity were obtained from Promega Corporation (Madison, WI, USA).

Identification of downstream targets of miR-340. To investigate the mechanism of the proapoptotic effect of miR-340, the online miRanda database (www.microrna.org) was searched to identify downstream targets of miR-340. The miR-mRNA interaction was searched, using the criteria of mirSVR score $<-0.2$ and PhastCons score $>0.5$.

Statistical analysis. SPSS software (version 19.0; IBM Corp., Armonk, NY, USA) was used to perform statistical tests. All data are presented as the mean \pm standard deviation. A one-way analysis of the variance and post hoc Student-Newman-Keuls test was used to test for statistically significant differences. 
$\mathrm{P}<0.05$ was considered to indicate a statistically significant significance.

\section{Results}

Curcumin induces the apoptosis of PANC-1 cells. As curcumin has previously been reported to exert anti-proliferative actions on pancreatic cancer cells, the effect of various doses of curcumin on the pancreatic cancer cell line PANC-1 was examined. Cells were treated with curcumin for $72 \mathrm{~h}$ and the effect on cell viability was investigated using an MTT assay. PANC-1 cell viability was decreased in a dose-dependent manner by curcumin, with the decrease being significant in cells treated with 5,10 or $20 \mu \mathrm{m}$ curcumin compared with the control group $(\mathrm{P}<0.05$; Fig. 1A). In addition, western blot analysis revealed that the expression of cleaved caspase-3, an apoptotic marker, was increased in a dose-dependent manner by curcumin, with this difference again being significant in cells treated with 5,10 or $20 \mu \mathrm{m}$ curcumin compared with the control group $(\mathrm{P}<0.05$; Fig. 1B). Consistent with previous reports, these results indicated that curcumin induces the apoptosis of pancreatic cancer cells.

miR-340 confers the proapoptotic effect of curcumin. To explore the potential molecular mechanism underlying the antitumor effect of curcumin, the effects of curcumin treatment on the level of miR-340, a previously characterized tumor-suppressive miRNA, was investigated. Notably, miR-340 levels were significantly elevated following treatment with 5,10 or $20 \mu \mathrm{M}$ curcumin $(\mathrm{P}<0.05$ vs. the control group; Fig. 2A). Overexpression of miR-360 significantly increased caspase-3 cleavage compared with the NC group $(\mathrm{P}<0.05$; Fig. 2B and C), and PARP, a substrate of caspase-3, was cleaved as a result (Fig. 2B and D). The cotreatment of PANC-1 cells with $10 \mu \mathrm{M}$ curcumin and anti-miR-340 significantly inhibited caspase- 3 and PARP cleavage $(\mathrm{P}<0.05$ vs. curcumin treatment alone; Fig. 2B-D). These results suggest that miR-340 is a positive regulator of apoptosis and acts as a downstream effector of curcumin in pancreatic cancer cells.

$X I A P$ is a target of $m i R-340$. To investigate the mechanism of the proapoptotic effect of $\mathrm{miR}-340$, the online miRanda database was searched to identify downstream targets of miR-340. The 3'-UTR of XIAP was analyzed and a potential incomplete base pair match with miR-340 was identified (Fig. 3A). A luciferase reporter assay revealed that overexpression of miR-340 significantly reduced luciferase activity compared with the NC group $(\mathrm{P}<0.05)$, an effect that was partially rescued with anti-miR-340 (Fig. 3B). Consistent with this result, miR-340 and anti-miR-340 exerted opposing effects on XIAP protein expression (Fig. 3C and D). These results indicate a direct association between miR-340 and XIAP.

Curcumin activates the miR-340/XIAP signaling pathway. XIAP expression decreased in a dose-dependent manner following curcumin treatment, which was significant in cells treated with 10 or $20 \mu \mathrm{M}$ curcumin compared with the control group ( $\mathrm{P}<0.05$; Fig. 4A and B). Similarly, miR-340 overexpression led to a significant decrease in XIAP expression compared with the NC group $(\mathrm{P}<0.05)$, whereas anti-miR-340 treatment rescued XIAP expression in the presence of $10 \mu \mathrm{M}$ curcumin (Fig. 4C and D). These results indicate that the miR-340/XIAP signaling pathway serves a role in the curcumin-induced apoptosis of pancreatic cancer cells.

\section{Discussion}

Developing an effective treatment strategy for pancreatic cancer remains a significant challenge worldwide. It has been suggested that miRNAs could form the basis for novel cancer treatments; however, there are limited successful delivery methods for miRNAs and they exhibit relatively low bioavailability. Curcumin has been demonstrated to alter the expression profile of a number of miRNAs in pancreatic cancer (22). Data from the present study confirmed that curcumin exerts an antitumor effect on PANC-1 cells by inducing apoptotic cell death. Notably, miR-340 was significantly upregulated following curcumin treatment. Curcumin treatment significantly decreased XIAP expression; however, silencing endogenous miR-340 abrogated the proapoptotic effect of curcumin and increased XIAP expression, suggesting that the miR-340/XIAP signaling pathway is responsible for the proapoptotic effect of curcumin. To the best of our knowledge, the present study clarifies for the first time that the miR-340/XIAP pathway is associated with the antitumor action of curcumin. These findings may also aid in the development of targeted treatments for patients with pancreatic cancer.

Previous studies have demonstrated that miR-340 serves an antitumor role in several types of cancers (25-27). A number of mechanisms have been proposed to explain this effect. For example, a set of negative regulators of p27 have been demonstrated to be targeted by miR-340 in non-small cell lung cancer (NSCLC) (27). Notably, clinical data supports an inverse association between miR-340 and disease progression in patients with NSCLC (27). In addition, several oncogenic signaling pathways and associated proteins, including the Ras GTPase/RAF-proto-oncogene serine/threonine-protein kinase/mitogen-activated protein kinase 1 signaling pathway, Rho-associated protein kinase 1 and proto-oncogene c-Met are modulated by miR-340 $(23,28,29)$, which suggests that miR-340 may function upstream of a series of positive regulators of cancer cell survival. The results from the present study demonstrated a tumor suppressive role for miR-340 in pancreatic cancer, identified XIAP as a target of miR-340 and identified a mechanism by which miR-340 induces apoptosis.

Curcumin is a natural compound extracted from the plant C. longa. Despite the previously demonstrated antitumor activity of curcumin, the mechanism underlying this effect remains elusive. Epigenetic changes induced by curcumin may mediate its effects (30). Previous studies have revealed that the expression of a number of miRNAs is altered by curcumin. Ye et al (31) demonstrated that cellular tumor antigen p53 (p53) is upregulated following curcumin treatment, and that the miR-192/XIAP signaling pathway is a downstream target of p53 that mediates the effects of curcumin treatment in NSCLC. Ma et al (21) demonstrated that miR-7 mediates the tumor suppressive effects of curcumin in pancreatic cancer cells. Similarly, the present study demonstrated that curcumin increases miR-340 expression in pancreatic cancer cells. The aforementioned studies by Ma et al (21) and Ye et al (31) 
A

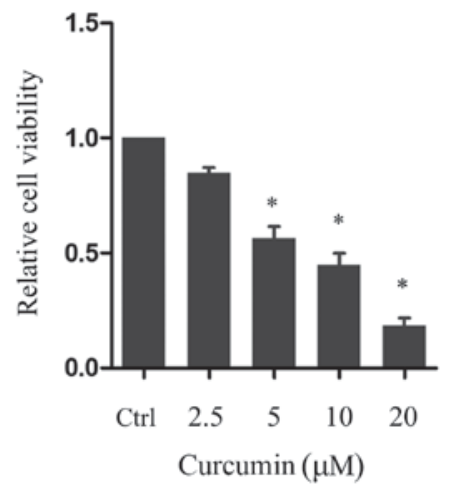

B
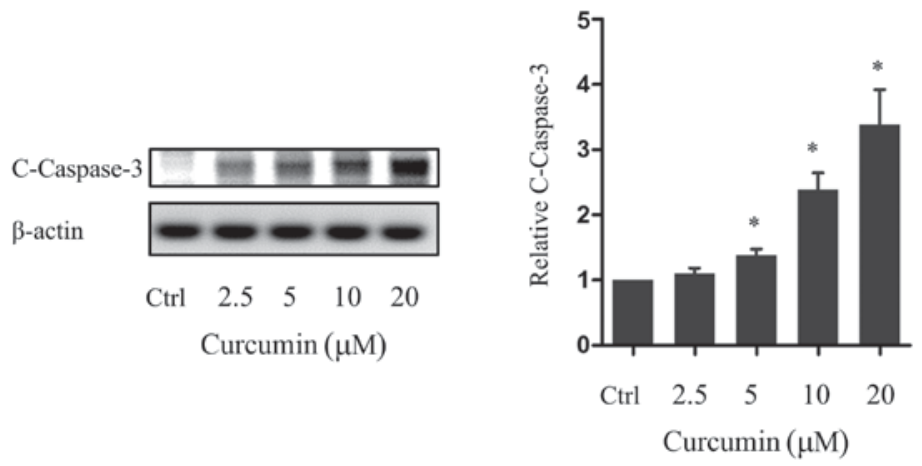

Figure 1. Curcumin induces apoptosis in PANC-1 cells. (A) Viability of PANC-1 cells following curcumin treatment relative to the Ctrl. (B) Western blot and quantification of $\mathrm{C}$-caspase-3 expression following curcumin treatment. ${ }^{*} \mathrm{P}<0.05$ vs. the $\mathrm{Ctrl}$. $\mathrm{n}=5$. C-, cleaved; Ctrl, control group.

A

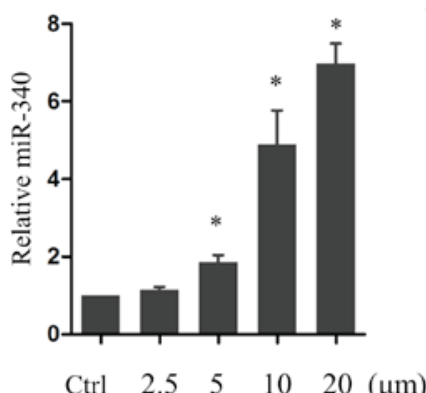

C

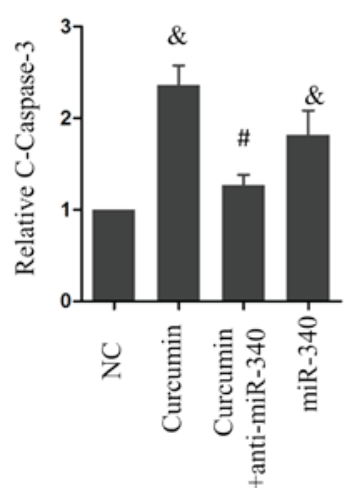

B

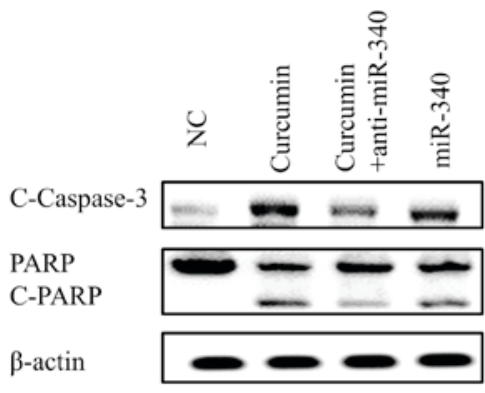

D

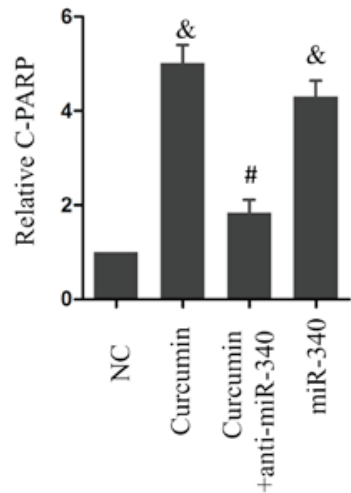

Figure 2. miR-340 is required for the curcumin-induced apoptosis of PANC-1 cells. (A) Relative expression of miR-340 following curcumin treatment (B) Expression of C-caspase-3 and C-PARP following treatment with $10 \mu \mathrm{M}$ curcumin alone, curcumin and anti-miR-340, or miR-340. Relative expression of (C) C-caspase-3 and (D) C-PARP following treatment with $10 \mu \mathrm{M}$ curcumin alone, $10 \mu \mathrm{M}$ curcumin and anti-miR-340, or miR-340. "P<0.05 vs. the Ctrl; ${ }^{\&} \mathrm{P}<0.05$ vs. the NC group; ${ }^{\mathrm{P}} \mathrm{P}<0.05$ vs. the curcumin group. $\mathrm{n}=5$. miR, microRNA; $\mathrm{C}-$, cleaved; PARP, poly(ADP-ribose) polymerase; NC, negative control; Ctrl, control group. 
A

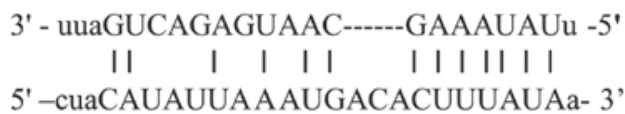

hsa-miR-340

5 ' -cuaCAUAUUAAAUGACACUUUAUAa- 3'

3'UTR of XIAP

B

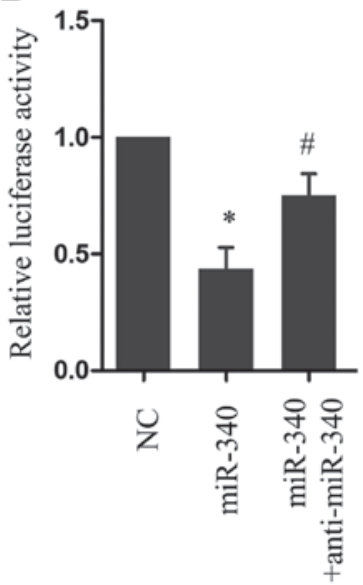

C

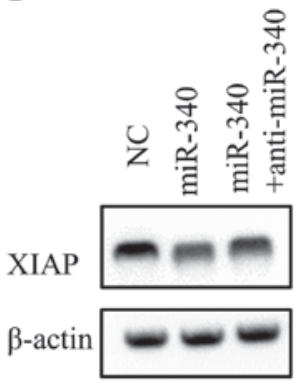

D

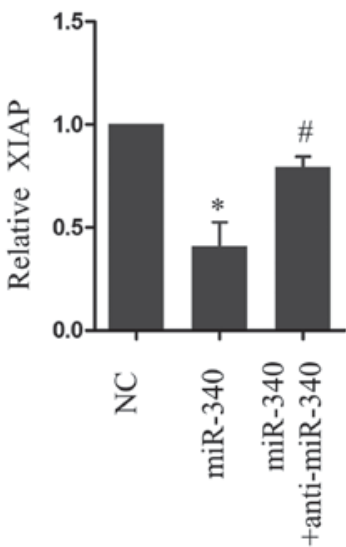

Figure 3. XIAP is a target of miR-340. (A) Schematic diagram of the putative binding site of miR-340 in the 3'-UTR of XIAP. (B) Relative luciferase activity following miR-340 or anti-miR-340 treatment. Western blot (C) image and (D) quantification of XIAP expression in PANC-1 cells following miR-340 and anti-miR-340 treatment. ${ }^{*} \mathrm{P}<0.05$ vs. the NC group, ${ }^{*} \mathrm{P}<0.05$ vs. miR-340. $\mathrm{n}=5$. XIAP, $\mathrm{X}$-linked inhibitor of apoptosis; UTR, untranslated region; miR, microRNA; NC, negative control.

A

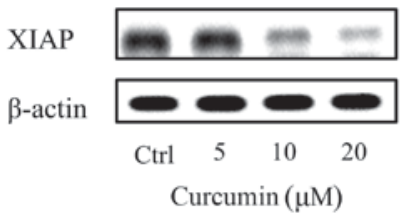

C

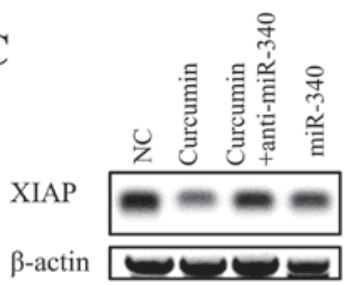

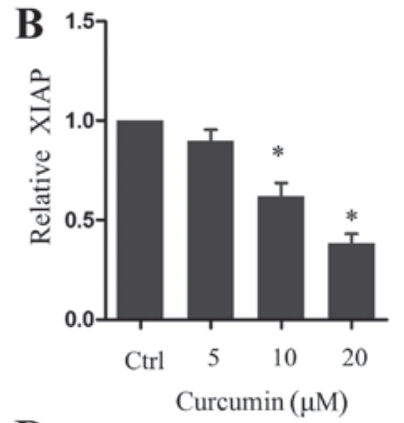

D

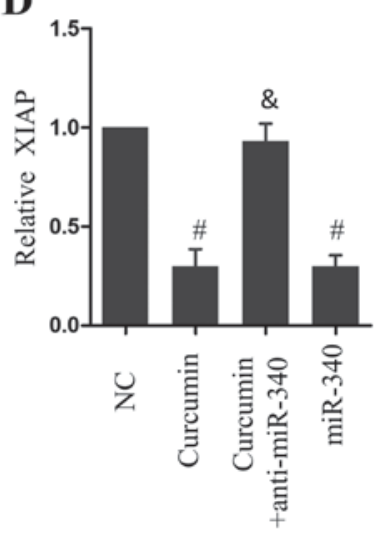

Figure 4. Involvement of the miR-340/XIAP signaling pathway in the curcumin-induced apoptosis of PANC-1 cells. Western blot (A) image and (B) quantification of XIAP expression following curcumin treatment. Western blot (C) image and (D) quantification of XIAP expression following treatment with $10 \mu \mathrm{M}$ curcumin alone, $10 \mu \mathrm{M}$ curcumin and anti-miR-340, or miR-340. " $\mathrm{P}<0.05$ vs. the $\mathrm{Ctrl}$; ${ }^{\prime} \mathrm{P}<0.05$ vs. the $\mathrm{NC}$ group; ${ }^{\&} \mathrm{P}<0.05$ vs. the curcumin group. $\mathrm{n}=5$. miR, microRNA; XIAP, X-linked inhibitor of apoptosis; Ctrl, control; NC, negative control.

demonstrated increased p53 expression following curcumin treatment. The expression of a number of antitumor miRNAs is regulated by p53 (32). However, whether miR-340 is regulated by $\mathrm{p} 53$ remains unclear and requires further investigation.
Data from the present study indicated that XIAP is a target of miR-340. XIAP inhibits caspase activity and subsequently inhibits apoptosis (33); however, following curcumin treatment, XIAP expression was identified to decrease as a result of increased miR-340 expression, resulting in the proapoptotic 
effect of curcumin. XIAP expression has previously been associated with cancer development and progression (34). In addition, previous clinical studies have revealed that XIAP may function as a biomarker for various types of cancer (33,35-37). Data from the present study demonstrated that the miR-340/XIAP signaling pathway serves a role in curcumin-induced apoptosis, which suggests that modulating this pathway may synergistically enhance the effect of curcumin. Notably, the results of the present study do not exclude the possibility of the involvement of other signaling pathways downstream of curcumin and miR-340. Due to the pleiotropic effects of natural compounds, other mechanisms may contribute to the pro-apoptotic effect of curcumin.

In conclusion, the data from the present study demonstrated that the miR-340/XIAP signaling pathway serves a role in the curcumin-induced apoptosis of pancreatic cancer cells. This suggests that administering the natural compound curcumin or modulating endogenous miR-340 expression may be effective treatment strategies for patients with pancreatic cancer.

\section{References}

1. Bond-Smith G, Banga N, Hammond TM and Imber CJ: Pancreatic adenocarcinoma. BMJ 344: e2476, 2012.

2. Ryan DP, Hong TS and Bardeesy N: Pancreatic adenocarcinoma. N Engl J Med 371: 1039-1049, 2014.

3. Casas-Grajales S and Muriel P: Antioxidants in liver health. World J Gastrointest Pharmacol Ther 6: 59-72, 2015.

4. He Y, Yue Y, Zheng X, Zhang K, Chen S and Du Z: Curcumin, inflammation, and chronic diseases: How are they linked? Molecules 20: 9183-9213, 2015.

5. Shanmugam MK, Rane G, Kanchi MM, Arfuso F, Chinnathambi A, Zayed ME, Alharbi SA, Tan BK, Kumar AP and Sethi G: The multifaceted role of curcumin in cancer prevention and treatment. Molecules 20: 2728-2769, 2015.

6. Zhao Z, Li C, Xi H, Gao Y and Xu D: Curcumin induces apoptosis in pancreatic cancer cells through the induction of forkhead box $\mathrm{O} 1$ and inhibition of the PI3K/Akt pathway. Mol Med Rep 12: 5415-5422, 2015.

7. Bimonte S, Barbieri A, Palma G, Luciano A, Rea D and Arra C: Curcumin inhibits tumor growth and angiogenesis in an orthotopic mouse model of human pancreatic cancer. Biomed Res Int 2013: 810423, 2013.

8. Youns M and Fathy GM: Upregulation of extrinsic apoptotic pathway in curcumin-mediated antiproliferative effect on human pancreatic carcinogenesis. J Cell Biochem 114: 2654-2665, 2013

9. Shakibaei M, Mobasheri A, Lueders C, Busch F, Shayan P and Goel A: Curcumin enhances the effect of chemotherapy against colorectal cancer cells by inhibition of $\mathrm{NF}-\kappa \mathrm{B}$ and Src protein kinase signaling pathways. PLoS One 8: e57218, 2013.

10. James MI, Iwuji C, Irving G, Karmokar A, Higgins JA, Griffin-Teal N, Thomas A, Greaves P, Cai H, Patel SR, et al: Curcumin inhibits cancer stem cell phenotypes in ex vivo models of colorectal liver metastases, and is clinically safe and tolerable in combination with FOLFOX chemotherapy. Cancer Lett 364: 135-141, 2015.

11. Wang BL, Shen YM, Zhang QW, Li YL, Luo M, Liu Z, Li Y, Qian ZY, Gao X and Shi HS: Codelivery of curcumin and doxorubicin by MPEG-PCL results in improved efficacy of systemically administered chemotherapy in mice with lung cancer. Int J Nanomedicine 8: 3521-3531, 2013.

12. Kasi PD, Tamilselvam R, Skalicka-Woźniak K, Nabavi SF Daglia M, Bishayee A, Pazoki-Toroudi $\mathrm{H}$ and Nabavi SM: Molecular targets of curcumin for cancer therapy: An updated review. Tumour Biol 37: 13017-13028, 2016.

13. Shehzad A and Lee YS: Molecular mechanisms of curcumin action: Signal transduction. Biofactors 39: 27-36, 2013.

14. Sharma P and Sharma R: miRNA-mRNA crosstalk in esophageal cancer: From diagnosis to therapy. Crit Rev Oncol Hematol 96 449-462, 2015.

15. Orellana EA and Kasinski AL: MicroRNAs in cancer: A historical perspective on the path from discovery to therapy. Cancers (Basel) 7: 1388-1405, 2015.
16. Chitkara D, Mittal A and Mahato RI: miRNAs in pancreatic cancer: Therapeutic potential, delivery challenges and strategies. Adv Drug Deliv Rev 81: 34-52, 2015.

17. Gayral M, Jo S, Hanoun N, Vignolle-Vidoni A, Lulka H, Delpu Y, Meulle A, Dufresne M, Humeau M, Chalret du Rieu M, et al: MicroRNAs as emerging biomarkers and therapeutic targets for pancreatic cancer. World J Gastroenterol 20: 11199-11209, 2014.

18. Khan S, Ansarullah, Kumar D, Jaggi M and Chauhan SC: Targeting microRNAs in pancreatic cancer: Microplayers in the big game. Cancer Res 73: 6541-6547, 2013.

19. Tormo E, Pineda B, Serna E, Guijarro A, Ribas G, Fores J, Chirivella E, Climent J, Lluch A and Eroles P: MicroRNA profile in response to Doxorubicin treatment in breast cancer. J Cell Biochem 116: 2061-2073, 2015

20. Hou N, Han J, Li J, Liu Y, Qin Y, Ni L, Song T and Huang C: MicroRNA profiling in human colon cancer cells during 5-fluorouracil-induced autophagy. PLoS One 9: e114779, 2014.

21. Ma J, Fang B, Zeng F, Pang H, Zhang J, Shi Y, Wu X, Cheng L, Ma C, Xia J and Wang Z: Curcumin inhibits cell growth and invasion through up-regulation of miR-7 in pancreatic cancer cells. Toxicol Lett 231: 82-91, 2014.

22. Sun M, Estrov Z, Ji Y, Coombes KR, Harris DH and Kurzrock R: Curcumin (diferuloylmethane) alters the expression profiles of microRNAs in human pancreatic cancer cells. Mol Cancer Ther 7: 464-473, 2008.

23. Zhou X, Wei M and Wang W: MicroRNA-340 suppresses osteosarcoma tumor growth and metastasis by directly targeting ROCK1. Biochem Biophys Res Commun 437: 653-658, 2013.

24. Livak KJ and Schmittgen TD: Analysis of relative gene expression data using real-time quantitative PCR and the 2(-Delta Delta C(T)) Method. Methods 25: 402-408, 2001.

25. Huang D, Qiu S, Ge R, He L, Li M, Li Y and Peng Y: miR-340 suppresses glioblastoma multiforme. Oncotarget 6: 9257-9270, 2015.

26. Li X, Gong X, Chen J, Zhang J, Sun J and Guo M: miR-340 inhibits glioblastoma cell proliferation by suppressing CDK6, cyclin-D1 and cyclin-D2. Biochem Biophys Res Commun 460: 670-677, 2015.

27. Fernandez S, Risolino M, Mandia N, Talotta F, Soini Y, Incoronato M, Condorelli G, Banfi S and Verde P: miR-340 inhibits tumor cell proliferation and induces apoptosis by targeting multiple negative regulators of p27 in non-small cell lung cancer. Oncogene 34: 3240-3250, 2015

28. Poenitzsch Strong AM, Setaluri V and Spiegelman VS: MicroRNA-340 as a modulator of RAS-RAF-MAPK signaling in melanoma. Arch Biochem Biophys 563: 118-124, 2014.

29. Wu ZS, Wu Q, Wang CQ, Wang XN, Huang J, Zhao JJ, Mao SS, Zhang GH, Xu XC and Zhang N: miR-340 inhibition of breast cancer cell migration and invasion through targeting of oncoprotein c-Met. Cancer 117: 2842-2852, 2011.

30. Teiten $\mathrm{MH}$, Dicato $\mathrm{M}$ and Diederich $\mathrm{M}$ : Curcumin as a regulator of epigenetic events. Mol Nutr Food Res 57: 1619-1629, 2013.

31. Ye M, Zhang J, Zhang J, Miao Q, Yao L and Zhang J: Curcumin promotes apoptosis by activating the p53-miR-192-5p/215-XIAP pathway in non-small cell lung cancer. Cancer Lett 357: 196-205, 2015.

32. Hünten S, Kaller M, Drepper F, Oeljeklaus S, Bonfert T, Erhard F, Dueck A, Eichner N, Friedel CC, Meister G, et al: p53-regulated networks of protein, mRNA, miRNA, and lncRNA expression revealed by integrated pulsed stable isotope labeling with amino acids in cell culture (pSILAC) and next generation sequencing (NGS) analyses. Mol Cell Proteomics 14: 2609-2629, 2015.

33. Deveraux QL and Reed JC: IAP family proteins-suppressors of apoptosis. Genes Dev 13: 239-252, 1999.

34. Wilkinson JC, Cepero E, Boise LH and Duckett CS: Upstream regulatory role for XIAP in receptor-mediated apoptosis. Mol Cell Biol 24: 7003-7014, 2004.

35. Srivastava AK, Singh PK, Singh D, Dalela D, Rath SK, Goel MM and Bhatt ML: Evaluation of urinary XIAP as a diagnostic biomarker of carcinoma of urinary bladder. Tumour Biol 35: 8243-8248, 2014

36. Xu YC, Liu Q, Dai JQ, Yin ZQ, Tang L, Ma Y, Lin XL and Wang HX: Tissue microarray analysis of X-linked inhibitor of apoptosis (XIAP) expression in breast cancer patients. Med Oncol 31: 764, 2014.

37. Baykara M, Yaman M, Buyukberber S, Tufan G, Demirci U, Benekli M, Coskun U, Ozet A and Umit Bagriacik E: Clinical and prognostic importance of XIAP and USP8 in advanced stages of non-small cell lung cancer. J BUON 18: 921-927, 2013. 